\title{
O PROGRAMA MAIS ALFABETIZAÇÃO NA REALIDADE DE MACEIÓ - ALAGOAS
}

\author{
Alana Laís de Araújo Almeida Silva ${ }^{1}$ \\ Erick Rodrigues da Rocha ${ }^{2}$ \\ Givanildo da Silva ${ }^{3}$
}

\begin{abstract}
RESUMO
A discussão sobre a alfabetização é um processo complexo a qual exige diferentes perspectivas e caminhos para uma visão ampla das tensões que a envolve. 0 objetivo da presente pesquisa foi perceber a organização e os desafios do Programa Mais Alfabetização no contexto de uma escola pública de Maceió, no estado de Alagoas. A questão norteadora que permeou o estudo foi: como se dá a organização do Programa Mais Alfabetização na realidade das escolas públicas e quais são os seus desafios para a efetivação das propostas presentes em suas diretrizes? A metodologia esteve pautada na abordagem qualitativa, tendo o estudo de caso como técnica da pesquisa. A coleta de dados foi realizada por meio da entrevista semiestruturada com oito participantes da escola, envolvidos diretamente com o objeto de estudo. Como resultados, ficou evidente que a concepção posta no Programa vai de encontro à defesa de uma formação continuada dos profissionais da educação, bem como assume a desvalorização docente através da precarização de contrato dos assistentes, concretizando uma concepção mínima de educação, sendo respaldada pelas políticas de cunho neoliberais.
\end{abstract}

Palavras-chave: Alfabetização. Programa Mais Alfabetização. Política Nacional de Alfabetização.

\section{THE MORE LITERACY PROGRAM IN THE REALITY OF MACEIÓ - ALAGOAS}

\begin{abstract}
Discussing literacy is a complex process that requires different perspectives and paths for a broad view of the tensions that surround it. The objective of this research was to understand the organization and challenges of the More Literacy Program in the context of a public school in Maceió, in the state of Alagoas. The guiding question that permeated the study was: how is the Mais Literacy Program organized

\footnotetext{
${ }^{1}$ Graduanda do Curso de Pedagogia da Universidade Federal de Alagoas, campus A. C. Simões, Maceió, Alagoas, Brasil. ORCID: http://orcid.org/0000-0001-7440-1008. E-mail: alana.lais.almeida@hotmail.com

2 Graduando do Curso de Pedagogia da Universidade Federal de Alagoas, campus A. C. Simões, Maceió, Alagoas, Brasil. ORCID: http://orcid.org/0000-0001-8100-7543. E-mail: rochaerick021@gmail.com

3 Doutor em Educação. Professor do Centro de Educação e Programa de Pós-graduação da Universidade Federal de Alagoas, campus A. C. Simões, Maceió, Alagoas, Brasil. ORCID: http://orcid.org/0000-0001-5490-6690. E-mail: givanildopedufal@gmail.com
} 
in the reality of public schools and what are its challenges for the implementation of the proposals contained in its guidelines? The methodology was based on the qualitative approach, with the case study as a research technique. Data collection was performed through a semi-structured interview with eight school participants, directly involved with the object of study. As a result, it became evident that the conception put in the Program goes against the defense of a continuous training of education professionals, as well as assumes the teacher devaluation through the precariousness of the assistants' contract, realizing a minimal conception of education, being supported by the policies of neoliberal nature.

Keywords: Literacy. More Literacy Program. National Literacy Policy.

\section{EL PROGRAMA MÁS ALFABETIZACIÓN EN LA REALIDAD DE MACEIÓ - ALAGOAS}

\section{RESUMEN}

Discutir la alfabetización es un proceso complejo que requiere diferentes perspectivas y caminos para una visión amplia de las tensiones que lo rodean. El objetivo de esta investigación fue comprender la organización y los desafíos del Programa Más Alfabetización en el contexto de una escuela pública en Maceió, en el estado de Alagoas. La pregunta guía que permeó el estudio fue: ¿̇cómo se organiza el Programa de Alfabetización Mais en la realidad de las escuelas públicas y cuáles son los desafíos para la implementación de las propuestas contenidas en sus directrices? La metodología se basó en el enfoque cualitativo, con el estudio de caso como técnica de investigación. La recolección de datos se realizó mediante una entrevista semiestructurada con ocho participantes de la escuela, directamente involucrados con el objeto de estudio. Como resultado, se hizo evidente que la concepción puesta en el Programa va en contra de la defensa de una formación continua de profesionales de la educación, y asume la devaluación del profesorado a través de la precariedad del contrato de los asistentes, realizando una concepción mínima de la educación, siendo respaldado por las políticas. de naturaleza neoliberal.

Palabras clave: Literatura. Más programa de alfabetización. Política nacional de alfabetización.

\section{INTRODUÇÃO}

As políticas educacionais são implementadas para garantir o direto de todos os cidadãos ao acesso à educação. Com isso, o processo de alfabetização vem sendo problematizado com o passar do tempo, em virtude das descontinuidades das políticas governamentais implementadas pelos governos, comprometendo, assim, o processo educativo (VIÉDES; ARANDA; SANTOS, 2019).

O objeto de estudo nesta pesquisa foi o Programa Mais Alfabetização (PMAILFA). O PMALFA objetiva colaborar com a alfabetização de crianças 
do $1^{\circ}$ e $2^{\circ}$ ano do ensino fundamental, por intermédio de um assistente em um trabalho junto ao professor regente, contribuindo com competências de leitura, de escrita e de Matemática com os estudantes. A carga horária pode ser distribuída entre 5 (cinco) a 10 (dez) horas semanais por turmas, com a finalidade de que o processo de alfabetização seja fortalecido nos dois primeiros anos iniciais do ensino fundamental.

O objetivo da pesquisa foi perceber a organização e os desafios do Programa Mais Alfabetização no contexto de uma escola pública de Maceió, no estado de Alagoas. A questão norteadora que permeou o estudo foi: como se dá a organização do Programa Mais Alfabetização na realidade das escolas públicas e quais são os seus desafios para a efetivação das propostas presentes em suas diretrizes?

A metodologia desenvolvida esteve pautada na abordagem qualitativa, considerando que ela responde a questões muito particulares (MINAYO, 1994). O método realizado na pesquisa foi o estudo de caso (YIN, 2010) em uma escola da rede municipal de Maceió. A coleta dos dados foi realizada por meio de entrevistas semiestruturadas com a diretora, a coordenadora pedagógica, 4 (quatro) professoras e 2 (duas) assistentes do Programa, lotados na escola pesquisada. As entrevistas foram realizadas individualmente, de acordo com a disponibilidade das participantes para a sua realização, no período de 29 de novembro de 2019 a 24 de janeiro de 2020.

O texto está estruturado em quatro partes que se completam, além da introdução e das considerações finais. Na primeira, evidenciam-se os conceitos de alfabetização, compreendendo-os como dimensão complexa. Na segunda, dialoga-se sobre a concepção de alfabetização posta na Política Nacional de Alfabetização (PNA), tendo em vista que ela repercute nas práticas escolares e nas ações desenvolvidas no âmbito social. $\mathrm{Na}$ terceira, apresentam-se as diretrizes organizativas do Programa Mais Alfabetização. E, por fim, na quarta parte, analisa-se o Programa Mais Alfabetização por meio das vozes dos participantes da pesquisa. 


\title{
Conceito de alfabetização
}

Levando em conta o processo de alfabetização no Brasil, a partir do período colonial até os dias atuais, interpassa por múltiplos conceitos, possibilitando variadas modificações. Na atualidade, há inúmeras discussões com estudiosos da área sobre a temática que promove o entendimento desse processo. A alfabetização no Brasil apresenta dificuldades em definir métodos que possibilitem aos alunos uma concepção de leitura e de escrita de forma integral. Para Soares (2018), essa temática é uma questão que atravessou o século XX e ainda persiste, recebendo, ao longo do tempo, sucessivas pretensas "soluções". Na visão da autora:

\begin{abstract}
Esteve presente, em nosso país, ao longo da história dos métodos de alfabetização, pelo menos desde as décadas finais do século XX, momento em que começa a consolidar-se um sistema público de ensino, trazendo a necessidade de implementação de um processo de escolarização que propiciasse às crianças o domínio da leitura e da escrita (SOARES, 2018, p.16).
\end{abstract}

O conceito de alfabetização, conforme Tfouni (2010), pode ser entendido por duas formas: ou como processo de aquisição individual de habilidades requeridas para leitura e escrita ou como um processo de representação de objetos diversos, de naturezas diferentes (TFOUNI, 2010).

Em relação à primeira concepção sobre alfabetização, aquisição individual de habilidades requeridas para leitura e escrita, ela é compreendida como função formal de escolarização no processo de codificação e decodificação, meramente ensinadas por instituições escolares. Na segunda perspectiva de alfabetização, representação de objetos diversos, não se leva em conta o processo de codificação e decodificação, isto é, não se aprende em um processo sistemático, mas de acordo com seu desenvolvimento, respeitando o seu processo de simbolização, tornando-se, assim, um processo complexo.

Soares define alfabetização como "[...]um processo de representação de fonemas em grafemas, e vice-versa, mas é também um processo de compreensão/expressão de significados por meio do código escrito [...]" (SOARES, 2018, p. 17-18). A concepção de alfabetização 
empregada por Soares contradiz a restrita concepção do sujeito em codificar (escrever) e decodificar (ler), mas a apropriação e aquisição em habilidades de leitura e de escrita empregadas pela língua. Desse modo, "sem dúvida, alfabetização é um processo de representação de fonemas em grafemas, e vice-versa, mas é também um processo de compreensão/expressão de significados por meio do código escrito" (SOARES, 2018, p.19).

Expresso em outros termos, o conceito de alfabetização vai além do processo de aquisição da língua escrita e oral, perpassa as relações práticas do ler e escrever, faz-se necessário levar em conta os fatores sociais das funções e os propósitos da aprendizagem considerando um conjunto de habilidades. Para a pesquisadora:

\begin{abstract}
A natureza complexa do processo de alfabetização evidencia, ainda, como tem sido apenas parcialmente enfrentado o problema da identificação dos pré-requisitos e da preparação da criança para a alfabetização. Essa questão ainda está restrita apenas uma faceta do processo de alfabetização, à faceta psicofisiológica; é necessário ampliar a visão do processo e acrescentar, à análise dos prérequisitos e à organização de programas de preparação para a alfabetização, o enfoque da psicologia cognitiva, da psicolinguística, da sociolinguística e da linguística (SOARES, 2018, p. 27-28).
\end{abstract}

Essas habilidades estão relacionadas às diferentes áreas atuantes, multifacetadas que carecem de uma articulação e integração com suas diferentes particularidades referentes às perspectivas psicológica, psicolinguística, sociolinguística e linguística, incluindo também os fatores sociais, econômicos, culturais e políticos no processo de alfabetização (SOARES, 2018). A alfabetização é o primeiro contato da criança com a leitura e com a escrita, momento fundamental para a sua formação educacional e social.

[...] o processo de alfabetização deve levar à aprendizagem não de uma mera tradução do oral para o escrito, e deste para aquele, mas à aprendizagem de uma peculiar e muitas vezes idiossincrática relação fonemas-grafemas, de um outro código, que tem, em relação ao código oral, especificidade morfológica e sintática, autonomia de recursos de articulação do texto e estratégias próprias de expressão/compressão (SOARES, 2018, p. 18). 
O ato de alfabetizar apresenta fatores importantes para a formação do sujeito. Esses Processos não podem ser "banalizados" e mal trabalhados, pois a alfabetização é a base para a continuidade da criança no mundo letrado, de modo que se não tiverem uma boa base, esses déficits refletirão em ações futuras no processo de ensino e de aprendizagem. Dessa forma, o ato de alfabetizar passa por diversas dificuldades que influenciam diretamente a qualidade da sua elaboração. Com isso, o aluno vivencia dificuldades na apropriação do aprendizado, gerando fatores culminantes ao fracasso escolar.

\title{
A concepção de Alfabetização posta na Política Nacional de Alfabetização
}

Iniciada com a finalidade de uma política de Estado4, a PNA estabelece normas para alfabetização no Brasil. Com isso, o atual Plano Nacional de Educação (2014-2024), Lei 13.005, de 25 de junho de 2014, visa apresentar um planejamento para a educação no Brasil durante 10 anos, estabelecendo metas e estratégias que devem ser alcançadas por meio de ações em regime de colaboração entre os diferentes entes da federação (União, estados, municípios e Distrito Federal).

Entretanto, de acordo com o Decreto $n^{\circ}$ 9.765, de 11 de abril de 2019:

\begin{abstract}
A Política Nacional de Alfabetização (PNA) é uma política de Estado instituída para fomentar programas e ações voltados à alfabetização com base nas mais recentes evidências científicas, no intuito de melhorar a qualidade da alfabetização e combater o analfabetismo absoluto e funcional no território brasileiro. A PNA tem como um dos objetivos contribuir para a consecução das metas 5 e 9 do Plano Nacional de Educação (art. 4, II). (PNA, 2019; p.40).
\end{abstract}

De acordo com os princípios estabelecidos no documento da PNA, essa política tem por intuito estabelecer diretrizes para fomentar a qualidade do processo de alfabetização no país, objetivando a melhoria dos índices de alfabetização por meio do método fônico, focando nas habilidades de leitura e escrita do sistema alfabético. Assim, "o tema da alfabetização, fundamental para a vida escolar e para o pleno exercício da cidadania, é

\footnotetext{
${ }^{4}$ As políticas de Estado são ações que envolvem diferentes instâncias para a sua aprovação e executação, perpassando de um governo a outro. As políticas de governo são políticas de curta duração que estão relacionadas aos ideais do governo vigente (OLIVEIRA, 2011).
} 
trazido com todo o vigor para o centro da política pública educacional do país" (PNA, 2019, p. 5).

A PNA é uma política de Estado que propõe-se iniciar a alfabetização na educação infantil, apesar de não ser seu objetivo, rompendo com políticas e programas dos governos anteriores, divergindo da Base Nacional Comum Curricular (BNCC), implementando a educação familiar, valorizando e considerando apenas uma habilidade para alfabetizar, o método fônico, e que deverá ser baseada em evidências científicas.

Viédes, Sousa e Aranda (2019) salientam que, na história da educação, houve momentos alternados na utilização dos métodos para alfabetização, utilizando-se métodos sintéticos (alfabético, silábico, fônico), outras vezes os métodos analíticos (palavração, sentenciação, contos e historietas). Desse modo, "[...] todos eles, no entanto, possuem em comum o fato de se centrarem no ensino, ou seja, é a atuação do professor que ganha destaque no processo de apreensão do código escrito e de sua decodificação, sendo o professor, geralmente com o apoio de materiais didáticos [...]" (VIEDES; SOUSA; ARANDA, 2019, p. 23). Entretanto, na concepção posta pela PNA, em utilizar apenas o método fônico para esse processo, não seria suficiente para alfabetizar, pois a alfabetização é complexa (SOARES, 2018) e tem que ser trabalhada de diversas formas. Isso porque a alfabetização é um processo individual e particular de cada aluno, sendo respondido de diferentes formas.

Assim sendo, compreende-se que ao iniciar 0 processo de alfabetização na educação infantil, para a criança adquirir as competências de leitura e de escrita, deve-se levar em consideração as experiências culturais, políticas, econômicas e familiares vivenciadas em cada realidade, uma vez que essas dimensões influenciam diretamente na aquisição desse processo. Com isso, "[...] é indispensável analisar as realidades sociais, econômicas, culturais e políticas que a definem na construção dos métodos e materiais didáticos para esse processo, assim como a concepção do professor alfabetizador" (OLIVEIRA, 2014, p. 10-11). 
A primeira etapa da educação básica deve ser constituída por experiências de socialização, de brincadeiras, de descobertas constantes. A alfabetização, em seu sentido completo, não tem espaço para a educação infantil, uma vez que as crianças necessitam da vivência de múltiplas linguagens, divergindo dos aspectos sinalizados na PNA.

Antecipar o processo de alfabetização é negar às crianças importantes etapas e experiências do desenvolvimento cognitivo que são primordiais para o desenvolvimento de suas atividades motoras, físicas, sociais, culturais, linguagem oral, que são adquiridas no início da escolarização, auxiliando na construção da identidade dos sujeitos. Ao inserir a alfabetização na educação infantil, como sinalizado na proposta da PNA, coloca-se em risco toda concepção e estudos já existentes. Peres apud Rosário (2019) ressalta que envolver a alfabetização nesse período acaba realizando um retrocesso nas conquistas sobre as pesquisas. A pesquisadora enfatiza que:

[...] Tudo o que tem sido feito até agora na área foi conquistado a duras penas e com parcerias importantes, com participação social, pesquisas em universidades, investimento em pesquisas sobre Alfabetização. Ainda que haja alguns questionamentos, característicos do debate científico, isso resultou em um acúmulo de conhecimentos que permitiu que avançássemos na compreensão da Alfabetização [...]. (PERES apud ROSÁRIO, 2019, S/P).

A PNA apresenta a concepção de "alfabetização como o ensino das habilidades de leitura e de escrita em um sistema alfabético" (PNA, 2019, p. 18). Sabe-se que o conceito de alfabetização vai além das concepções apresentadas pela política, pois a alfabetização não se restringe a um único conceito. Com isso, "[...] ao compreender a escrita como sistema notacional, concebe-se que a alfabetização é um processo complexo que requer que o aprendiz compreenda as propriedades do Sistema de Escrita Alfabética [...]" (VIÉDES; SOUSA; ARANDA, 2019, p. 23).

Nessa perspectiva, a PNA tem foco na Ciência Cognitiva da Leitura com a utilização do método fônico. Com isso, "observa-se, assim, que a referida política compreende a alfabetização, de forma semelhante ao final 
do século XIX e início do século XX no Brasil, como uma questão de ensino, e não de aprendizagem. Desde que o professor siga fielmente o método [...]" (VIÉDES; SOUSA; ARANDA, 2019, p. 31). Em outros termos, para a política, se o professor seguir as instruções de acordo com o que é proposto, as dificuldades para aprendizagem serão sanadas. Porém, não se deve tratar a alfabetização como uma receita, visto que se sabe sobre a complexidade e as constantes individualizações para apropriação desse processo. Desse modo,

[...] compreende-se a opção, nesse programa, pela nomenclatura "ciclo de alfabetização", uma vez que se considera que a complexidade desse processo demanda conceber a criança como um sujeito ativo da aprendizagem, não um receptor de conteúdos transmitidos pelo professor, que precisa reconstruir intelectualmente o funcionamento do sistema de escrita alfabética e não somente memorizar e reproduzir as combinações possíveis entre as letras e sílabas (VIÉDES; SOUSA; ARANDA, 2019, p. 25).

O conceito de alfabetização apresentado pela PNA diverge com o de Magda Soares, visto que, para a autora, a alfabetização possui muitas facetas que precisam estar articuladas e integradas ao processo (SOARES, 2018). Alfabetizar não é somente codificar e decodificar o sistema alfabético e adotar um único método para ensinar, é um processo complexo que envolve conhecimentos de natureza psicológica, linguística e sociolinguística.

A PNA é precisa ao conceituar a alfabetização, deixando claro que, para uma criança ser considerada alfabetizada, necessita dominar as habilidades de leitura e escrita de um sistema alfabético. Nessa perspectiva, uma criança alfabetizada domina a técnica e as habilidades da escrita, do mesmo modo com o aprendizado da leitura. Para tanto, é necessário a utilização dos diversos gêneros textuais. Dominar essa competência demanda,

[...] desde a habilidade de transcrever a fala, via ditado, até habilidades cognitivas e metacognitivas; inclui a habilidade motora (caligrafia), a ortografia, o uso adequado da pontuação, a habilidade de selecionar informações sobre determinado assunto, e de caracterizar o público como leitor, a habilidade de estabelecer metas para a escrita e decidir qual a melhor forma de desenvolvê-la, a habilidade de organizar ideias em um texto escrito, estabelecer relações entre elas, expressá-las adequadamente. Além disso, as 
habilidades de escrita, tal como as de leitura, devem ser aplicadas diferenciadamente à produção de uma variedade de materiais escritos: da simples assinatura do nome à elaboração de uma lista de compras até a redação de um ensaio ou de uma tese de doutorado (SOARES, 1999, p. 70).

Como é possivel perceber, o processo de alfabetização é amplo, exige diferentes facetas e necessita ter diferentes olhares para uma melhor compreensão, uma vez que, "o processo de alfabetização é desafiador, tanto para o discente, que está sendo alfabetizado, quanto para o docente, a quem incube a responsabilidade de alfabetizar" (DIONIZIO; SOUZA, 2017, p. 187).

\section{O Programa Mais Alfabetização: princípios e normativas}

De acordo com a Constituição Federal da República Federativa do Brasil (1988), a educação é direito de todos, sendo dever do Estado e da família assegurar o desenvolvimento do indivíduo em aspectos sociais. No artigo 205, é evidenciado que "a educação, direito de todos e dever do Estado e da família, será promovida e incentivada com a colaboração da sociedade, visando ao pleno desenvolvimento da pessoa, seu preparo para o exercício da cidadania e sua qualificação para o trabalho" (BRASIL, 1988).

A Constituição Federal de 1988 apresenta os princípios para a educação em seu artigo 14, sinalizando, como dimensões importantes, a erradicação do analfabetismo; a universalização do atendimento escolar; a melhoria da qualidade do ensino; a formação para o trabalho; a promoção humanística, científica e tecnológica do País (BRASIL, 1988). Embora o inciso primeiro da Constituição Federal visa à erradicação do analfabetismo, o índice de analfabetismo no Brasil tem um aumento constante, devido a fatores econômicos, culturais e sociais. Assim, propondo melhorias para essa problemática, o Ministério da Educação, durante o governo Temer (20162018), elaborou o PMALFA na tentativa de romper com essa realidade, desconsiderando o Pacto Nacional de Alfabetização na Idade Certa (PNAIC), programa que estava em vigor na política educacional.

O Programa Mais Alfabetização foi constituído pelo Ministério da Educação através da portaria $n^{\circ} 142 / 2018$. O Programa tem como finalidade 
dar um suporte técnico e financeiro às instituições escolares que alfabetizam e ofertam regularmente estudantes matriculados nos $1^{\circ}$ e $2^{\circ}$ anos do ensino fundamental. No entanto, o "Programa é inserido em meio crise do Brasil, perante avaliações externas, de leitura/escrita e baixos índices de alfabetização, principalmente no tocante a português e matemática, nas avaliações internacionais, como PISA" (MORAES, 2019, p. 116). O Programa foi instituído em um contexto de avaliações em larga escala, desconsiderando as diferentes realidades e enfatizando o processo de escrita e de leitura como inerentes para o sucesso dos resultados das avaliações.

O PMALFA foi implementado em 2018 e tem como objetivo diminuir os índices de analfabetismo no Brasil, enfatizando o processo de alfabetização a partir do $1^{\circ}$ ano ao $2^{\circ}$ do ensino fundamental das escolas públicas, priorizando exclusivamente as disciplinas de Língua Portuguesa e Matemática, a serem reforçadas com o apoio do assistente. Conforme o Ministério de Educação, a promoção precoce para alfabetizar as crianças faz-se necessária devido aos resultados negativos da Avaliação Nacional de Alfabetização (ANA), entendendo que é preciso que as crianças desenvolvam mais cedo as competências necessárias para avançar nos demais processos de alfabetização.

O PMALFA é embasado em 10 diretrizes que regem seu funcionamento: Fortalecer o processo de alfabetização dos anos iniciais do ensino fundamental, por meio do atendimento às turmas de $1^{\circ}$ e $2^{\circ}$ anos; Promover a integração com a política educacional da rede de ensino; Integrar as atividades ao projeto político-pedagógico da rede e das unidades escolares; Viabilizar atendimento diferenciado às unidades escolares vulneráveis; Estipular metas do Programa entre o MEC, os entes federados e as unidades escolares participantes; Assegurar o monitoramento e a avaliação periódica da execução e dos resultados do Programa; Promover o acompanhamento sistemático, pelas redes de ensino e gestão escolar, da progressão da aprendizagem dos estudantes regularmente matriculados no $1^{\circ}$ e $2^{\circ}$ anos do ensino fundamental; Estimular a cooperação 
entre União, estados, Distrito Federal e municípios; Fortalecer a gestão pedagógica e administrativa das redes federal, estaduais, distrital e municipais de educação e de suas unidades escolares jurisdicionadas; Avaliar o impacto do Programa na aprendizagem dos estudantes, com o objetivo de gerar evidências para seu aperfeiçoamento (BRASIL, 2018).

Na visão de Moraes (2019), o programa é orientado pela visão neoliberal de educação, afastando-se do plano social para o favorecimento do capital. O PMALFA "seguindo a "lógica" neoliberal, os fundamentos pedagógicos e estruturantes do Programa baseiam-se em assistencialismo e retirada do Estado de sua função de gestor da educação pública" (MORAES, 2019, p. 117). Com isso, "a total ausência de conteúdos científicos, artístico e filosóficos e ênfase em métodos, procedimentos, competências e habilidades, atestam o predomínio da concepção neoliberal" (MORAES, 2019, p. 118).

O PMALFA objetiva colaborar com a alfabetização por intermédio de um assistente em um trabalho junto ao professor regente, desenvolvendo as competências de leitura, de escrita e de Matemática com os estudantes, a fim de que o processo de alfabetização seja fortalecido nos anos iniciais do ensino fundamental. Cada assistente tem oportunidade de auxiliar até 10 turmas, de acordo com a especificidade da escola. Assim, "a contratação do assistente de Alfabetização é voluntária numa função que deveria ser feita pelo Estado, em concurso, com professor habilitado para tal função e detentor de saber específico, com remuneração e direitos compatíveis" (MORAES, 2019, p. 123).

O papel do assistente é importante para o desenvolvimento do Programa, posto que sua função é auxiliar o professor regente com as crianças que possuem uma maior dificuldade de aprendizagem. No entanto, não é estabelecida uma formação na área da educação para atuar como assistente de sala de aula, precarizando o ensino ofertado, desqualificando o papel do profissional que promove a mediação do processo de ensino e de aprendizagem no ambiente escolar. 
Verifica-se que a desvalorização do profissional da educação pelos órgãos que promovem o programa não é unicamente na escolha dos profissionais que estão inseridos em sala de aula para dar um apoio, como também na remuneração, na medida em que é pago um valor de $R \$ 300$ reais por turmas de dez (10) horas, e $\mathrm{R} \$ 150$ por turmas de cinco (5) horas. As turmas de dez (10) horas são consideradas turmas vulneráveis, devido aos baixos índices do Índice de Desenvolvimento da Educação Básica (IDEB), por serem localizadas em áreas de difícil acesso, não ter boa estrutura física, entre outros fatores.

Ao analisar a formatação do PMALFA em contratar profissionais sem possuir formação acadêmica para exercer o papel de assistente, problematiza-se a concepção do professor alfabetizador, de modo que a alfabetização como processo complexo tem que ser exercida por um profissional capacitado, que possa contribuir diretamente no processo de apropriação da leitura e de escrita. Entretanto:

A alfabetização deve ser período de contato sistêmico e consciente da criança com a leitura e a escrita, intermediada pelo ato crítico de ensinar do professor, com ensino dos conteúdos clássicos escolares, na aquisição das primeiras letras e leituras. Nessa via entendemos ser essa a melhor forma de aprendizado e luta da escola pública democrática e cidadã, por meio da qual haja apropriações pelos estudantes do conhecimento científico, artístico, filosófico, considerando ser a escola o lócus privilegiado para tais apropriações (MORAES, 2019, p.121).

O PMALFA tem como preceitos promover a integração com a política educacional da rede de ensino, integrar as atividades ao Projeto Político Pedagógico da rede e das unidades escolares, estipular metas do Programa entre o MEC, os entes federados e as unidades escolares participantes, bem como assegurar o monitoramento e avaliação periódica da execução e dos resultados do Programa, além de estimular a cooperação entre União, estados, municípios e Distrito Federal, fortalecendo a gestão pedagógica e administrativa das redes federal, distrital, estaduais e municipais da educação e de suas unidades jurisdicionadas. 
Dessa forma, cabe ao Ministério da Educação atuar diretamente no monitoramento e estabelecimento de regras a serem seguidas, disponibilizando todo o aparato para o desenvolvimento e continuidade do programa nas escolas, dando autonomia para cada instituição ofertar capacitação aos profissionais e quais métodos serão utilizados para auxiliar no processo de alfabetização.

As Secretarias de Educação são incumbidas de : a) articular as ações do programa com vistas a fortalecer a política de alfabetização da rede; b) colaborar para a qualificação e a capacitação dos assistentes de alfabetização e professores alfabetizadores, em parceria com o MEC; c) planejar e executar as formações no âmbito do programa; d) garantir a aplicação das avaliações nos períodos estabelecidos; e) acompanhar sistematicamente a evolução da aprendizagem dos estudantes das escolas da rede de ensino; f) garantir a realização de processo seletivo simplificado que privilegie a qualificação do assistente de alfabetização (BRASIL, 2018).

As unidades escolares ficam responsáveis em executar o projeto, informando ao MEC a seleção dos assistentes e conciliando as atividades com o Projeto Político-Pedagógico da instituição, além de realizar aplicação das avaliações diagnósticas com intuído de verificar a evolução dos alunos participantes do programa.

\section{O Programa Mais Alfabetização na realidade de Maceió-Alagoas}

A escola na qual foi feita a presente pesquisa está situada em um bairro periférico capital alagoana. Possui 12 turmas com um total de 289 alunos nos turnos matutino e vespertino, ofertando o ensino fundamental do $1^{\circ}$ ao $5^{\circ}$ ano. O Programa Mais Alfabetização foi implementado na instituição no ano de 2018, com a finalidade de melhorar os níveis de aprendizagem dos alunos de $1^{\circ}$ e $2^{\circ}$ anos.

De acordo com a diretora da escola, o programa está ajustado com a BNCC, que objetiva o processo de alfabetização até o $2^{\circ}$ ano, em virtude da maioria das escolas públicas só conseguirem alfabetizar a partir do $3^{\circ}$ ano, 0 
PMALFA favoreceu o nível de leitura, escrita e Matemática aos $1^{\circ}$ e $2^{\circ}$ anos Ensino Fundamental.

A visão apresentada sobre o processo de alfabetização até $\circ 2^{\circ}$ ano vai de encontro às pesquisas de Soares (2018), quando sinaliza que não há um período específico para o processo de alfabetização. De acordo com Soares (2018), não há como delimitar uma idade certa para iniciar e finalizar - processo de alfabetização, dado que cada aluno tem seu tempo de desenvolvimento individual para o processo de aprendizagem.

Ficou evidente, ao analisar os dados coletados, que o PMALFA foi configurado na escola com intuito de sanar as dificuldades recorrentes dos alunos em relação à leitura, à escrita e Matemática. Segundo Morais, "[...] o Programa Mais Alfabetização pauta-se em ação assistencialista da educação, em que fomentos são oferecidos em lugares "mais pobres" e com "baixos índices", com visão de educação hegemônica, de educação unilateral [...] (MORAIS, 2019, p.118). Com isso, na visão da diretora, o programa objetiva "acompanhar, apoiar, orientar o professor e o assistente de alfabetização; lançar e atualizar os dados do programa no sistema" (DIRETORA DA ESCOLA).

Para a professora 4 (quatro), o programa tem o intuito de "auxiliar o trabalho do professor alfabetizador, para fins de aquisição de competências de leitura, escrita e matemática para os estudantes" (PROFESSORA 4). Assim sendo, o programa tem finalidade de auxílio, para dar suporte as competências básicas propostas.

De acordo com a professora 3 (três), no desenvolvimento das atividades, na sala de aula, o assistente fica com um grupo mais avançado, a fim de que ela possa dar uma assistência maior aos alunos que possuem uma maior dificuldade no processo de alfabetização, para que eles consigam acompanhar os demais alunos que estão em um nível mais avançado.

Foi possível perceber, por meio dos depoimentos das professoras 3 (três) e 4 (quatro), que a vivência do programa na escola possibilitou o desenvolvimento de atividades com os estudantes para que os níveis de 
alfabetização em suas respectivas turmas se equiparassem, mesmo compreendendo que cada aluno tem seu ritmo no processo de aprendizagem.

É importante ressaltar que os desafios vivenciados pela escola para a concretização do Programa estão divididos em dois pontos, um referente à estrutura física, sendo que, quando questionado, o assistente 1 (um) afirmou que os "[...] desafios com alunos eu não tenho. Mas, com a estrutura da escola, é a prefeitura repassar, eu acho que a gente tem que trabalhar com pouca coisa e dar mais de si [...]" (ASSISTENTE 1). O outro desafio é referente à formação dos assistentes que são selecionados para atuar com as crianças. Para a assistente 2 (dois):

São vários, para mim que fazia tanto tempo que não trabalhava
com crianças foi um desafio maior, porque criança requer mais
aproximação, um tempo maior próximo a eles e alfabetização é
uma coisa que não é pra todo mundo. O Programa Mais
Alfabetização eu fico muito triste porque ele foi aberto à pessoas que
não tem nada a ver com campo da educação. Esse foi o maior erro,
abrir para todas as áreas, porque para alfabetizar e a pessoa que
está em processo de alfabetização e aquisição de leitura e a escrita
é necessário que seja uma pessoa que tenha conhecimento
justamente esse preparo para poder ensinar (ASSISTENTE 2).

Como é possivel perceber nos depoimentos dos assistentes, a estrutura física do local e a falta de materiais didáticos são aspectos que influenciam diretamente para o processo de ensino e de aprendizagem. Por outro lado, a qualificação desses assistentes é outra problemática visível na seleção desses profissionais, visto que, para Morais, "na primeira parte do Programa observamos a sua concepção neoliberal, evidenciando a participação dos professores como ação voluntaria" (MORAIS, 2019, p. 121). E "em um segundo momento o Programa caracteriza, os "atores" envolvidos - e quais suas funções, observando a caraterização da escola como espaço empresarial, com funções de vigilância, supervisão e tecnocracia [...]" (MORAIS, 2019, p. 121). Em outras palavras, a desvalorização e os desafios do docente ao colocar um assistente "não qualificado" para realizar o auxílio, evidenciam a falta de legitimidade na qualidade desse processo. 
Nesse contexto, é possível afirmar que os assistentes selecionados para atuar no processo de alfabetização das crianças não estão preparados e não obtêm nenhuma especialização na área da educação. A prática de contribuir com a alfabetização das crianças é uma dimensão complexa, visto que o processo é complexo (SOARES, 2018), o qual requer conhecimentos e habilidades específicas, situação que os assistentes, pela falta de formação, não conseguem obter.

Sobre o papel dos assistentes, a professora 2 (dois) ressaltou:

[...] dá um auxílio realmente aos alunos, né? E ao professor pra dar esse desenvolvimento as crianças para que eles possam desenvolver melhor. Esse acredito que seja o papel do assistente. Mas, eles não são preparados, no caso eu falo é da minha situação, que eu vejo assim outros assistentes de colegas eu vejo que tem uma desenvoltura uma preparação, não sei se buscam ou se realmente são capacitados pra isso. Mas, no meu caso realmente não vejo essa capacitação, essa desenvoltura na sala pra tratar com os meninos (PROFESSORA 2).

Desse modo, percebe-se que a relação com 0 assistente é relativamente desconfortável, visto que esse assistente não tem uma preparação e qualificação para exercer esse papel. No que diz respeito à capacitação do assistente, e levando em conta o depoimento da professora 2 (dois), demonstrou-se que a SEMED, órgão responsável pela capacitação do profissional, não estava preparando os assistentes para a realidade da sala de aula, considerando que profissionais com o notório saber não dispõem de competências e habilidades equivalentes para a prática docente.

A coordenadora pedagógica destacou que a seleção dos assistentes foi feita pela Secretaria Municipal de Educação e que "a gente não sabe qual foi o critério que eles fizeram. Uma prova de conhecimentos gerais e de dependente creio eu, independente de qual curso tenha, né?" (COORDENADORA PEDAGÓGICA).

Dessa forma, nota-se que o modo como esses profissionais foram selecionados reflete a qualidade do processo elaborado pelos professores, influenciando diretamente na aprendizagem dos alunos. A formação específica em Pedagogia seria um item importante para contribuir com o 
processo de seleção dos assistentes, bem como para o direcionamento das práticas educativas. Nessa perspectiva, o programa favorece a precarização do docente, como Morais sinaliza:

A discussão acerca da precarização docente, contida no Programa Mais Alfabetização, parte da forma como é vista a formação continuada dos professores do $1^{\circ}$ e $2^{\circ}$ anos e sua participação no Programa, princípios esses que parecem não levar em conta ação do trabalho e formação continuada como ação reflexiva e crítica do trabalho a ser desenvolvido mediante a alfabetização nas salas de aula (MORAIS, 2019, p. 121).

É necessário evidenciar que, nas diretrizes do Programa, não há nenhuma referência acerca da formação continuada dos profissionais da educação e dos assistentes que lidam diretamente com o processo de ensino e de aprendizagem das crianças. Desse modo, reflete-se que a concepção posta no PMAILFA não valoriza a formação continuada como dimensão do aperfeiçoamento do docente e de sua ressignificação para uma melhoria da práxis, desconsiderando que o processo de aprendizagem é contínuo em qualquer idade e que, para os profissionais da educação consigam adaptar-se às mudanças sociais, culturais, tecnológicas, é preciso que se aprimorem, posto que essas mudanças são dinâmicas e influenciam diretamente no cotidiano das salas de aula, assim como os professores precisam estar preparados para o aperfeiçoamento da prática docente. Morais (2018) defende que a educação é um processo dialético, de ensino e de aprendizagem, que faz parte da história do ser humano, e esses processos são importantes para a concretização de saberes e práticas docentes.

Em relação à atuação dos assistentes, a sua formação e a sua experiência, são aspectos importantes para o êxito das atividades com os alunos. Quando questionados sobre a sua formação e experiência de atuação profissional, o assistente 1 (um) informou que atua "[...] há dois anos, eu sou formado em inglês e já atuei dois anos, não, nessa escola, em escola particular" (ASSISTENTE 1). Já a assistente 2 (dois) tem "formação em magistério, e já atuo na educação há 20 anos" (ASSISTENTE 2). 
Ao relatar a carga horária cumprida na escola, o assistente 1 (um) descreveu que "atualmente, é das 7 às 11, porque, como eu tenho outra escola, eu fico e meio horário na outra escola... na outra escola, eu trabalho como professor de inglês infantil" (ASSISTENTE 1). A assistente 2 (dois) afirmou que "É... eu atendo a duas turmas. A carga horária são (sic) 20 horas, sendo divididas 10 horas nesta escola e 10 horas em outra, aqui com uma turma de 10 horas e lá com duas turmas de 5 horas cada" (ASSISTENTE 2).

A remuneração recebida para atuação é irrisória, mostrando, assim, a desvalorização desses profissionais, uma vez que o assistente 1 (um) afirmou receber "atualmente são os 300,00 reais que são a carga horária de 20 horas" (ASSISTENTE 1). A assistente 2 (dois) confirmou esse valor, salientando receber "300 reais por turma" (ASSISTENTE 2). Desse modo, Morais problematiza a contratação, a remuneração desses assistentes, afirmando que

[...] a contratação do Assistente de Alfabetização é voluntaria numa função que deveria ser efetivada pelo Estado, em concurso, com professor habilitado para tal função e detentor de saber específico, com remuneração e direitos compatíveis. Porém, totalmente na contramão da legislação que permite tal exploração, ocorre a expropriação do trabalho docente, sem garantir-lhe o mínimo previsto na constituição e nas leis trabalhistas, mostrando total desserviço ao conjunto da classe trabalhadora [...] (MORAIS, 2019, p. 123).

As questões levantadas por Morais e os assistentes mostram o descaso com a educação pública e com a profissão docente, uma vez que o Estado, por meio de seus programas, fomenta, em seus editais, que, para ser um alfabetizador, não é necessário ter uma formação específica, basta ter noções básicas sobre o sistema de escrita alfabética, valorizando o notório saber, desconsiderando que profissionais desqualificados influenciam diretamente a aprendizagem do aluno.

A compreensão de alfabetização sobreposta pelo Programa não atende as necessidades reais da educação pública, uma vez que o Programa entende que alfabetizar é meramente o procedimento da aquisição do sistema de escrita alfabética, desrespeitando o processo 
complexo da alfabetização, no qual, sozinha, a criança não é capaz de desenvolver com eficiência o processo de aprendizagem da língua escrita.

Segundo Soares (2018), a alfabetização é apenas uma das facetas de aprendizagem da língua escrita, tendo em vista que a criança alfabetizada e letrada não precisa apenas saber ler e escrever, mas também compreende habilidades básicas de leitura e escrita, que possibilitam a sua autonomia de compreender, interpretar e criar textos, ou seja, a alfabetização é uma habilidade importante, mas não é suficiente.

No que concerne ao planejamento das aulas lecionadas pelo professor assistente, conforme a direção, elas são organizadas pela professora regente e a coordenação e executadas pelo auxiliar. Em contrapartida, as professoras relatam que não há um planejamento, uma vez que a falta de compatibilidade nos horários dificulta a execução do planejamento e resulta na improvisação das atividades da semana.

Segundo a professora 2 (dois), "o planejamento é muito conturbado, porque é... Não existe esse planejamento na realidade, né? É realmente fora do contexto do planejamento, do que é ideal ou o que deveria ser um planejamento" (PROFESSORA 2). Desse modo, "planejar significa entrever uma forma possível e desejável. Se não há planejamento, corre-se o risco de se desperdiçarem oportunidades muito interessantes" (VASCONCELLOS, 2002, p. 148).

Para os assistentes, o planejamento é feito por meio de uma conversa, na qual é dado um feedback ao professor regente e, a partir das conclusões, é feito um direcionamento para as próximas etapas. Dos assistentes entrevistados, apenas 0 assistente 2 (dois) faz o planejamento com a coordenação da escola, sendo assim, verifica-se que a falta de planejamento influencia na prática e execução das atividades.

Sabe-se que o planejamento é fundamental para que $\circ$ professor possa ter um direcionamento do que vai ser abordado no dia da aula, das atividades que serão aplicadas, pois, sem ele, a execução da aula torna-se desorganizada, levando ao desestímulo tanto do aluno quanto do docente, além de intervir no processo de alfabetização. Para o assistente 1 (um): 
Meu planejamento, eu converso com a professora, ela repassa pra mim as dificuldades que eles estão e o que eles têm que aprender ainda. Aí a gente conversa, a gente repassa um para o outro pra ver o que poderemos fazer e, na sala de aula, pratica. Feito um dia na semana na terça ou na quinta [...] (ASSITENTE 1).

Em concordância com o manual operacional do sistema de orientação pedagógica e de monitoramento do Programa, é responsabilidade do professor o planejamento e a articulação do Programa em sala de aula (BRASIL, 2018). Dessa forma, "o referido documento destaca ser o professor alfabetizador responsável pela supervisão do trabalho do assistente de alfabetização e pela interação do programa com Projeto Político Pedagógico da escola" (VIÉDES; ARANDA; SANTOS, 2018, p.5). Assim, o planejamento deveria ser realizado de forma conjunta professor/assistente, sendo articulado com PPP da escola, visando melhorias nas atividades elaboradas e no processo de aprendizagem dos alunos, visto que "não planejar pode implicar perder possibilidades de melhores caminhos, perder pontos de entrada significativos" (VASCONCELLOS, 2002, p. 148).

Sendo assim, o Programa Mais Alfabetização é avaliado pelos participantes com pontos positivos e negativos que serviram para melhorar o desempenho e o fortalecimento do processo de alfabetização, de modo que, no geral, um ponto em comum é que todos concordam, de forma unânime, que a presença de um auxiliar ajudou ao professor regente em suas práticas educativas em sala de aula. Como é evidenciado pela coordenadora ao afirmar que: "o ponto positivo é quando realmente chega o assistente. né? Dá uma... O professor titular tem mais condições de trabalhar com o grupo que precisa de mais atenção, porque com 20-25 alunos em uma sala é muito complicado[...]" (COORDENADORA). Dessa forma, para professora 2 (dois), "os positivos é que eu acho que o objetivo seria realmente de ajudar o aluno. Mas, a gente não tem um conhecimento a fundo desse programa e as pessoas que vêm, algumas não são preparadas, então esse é um ponto negativo[...]" (PROFESSORA 2).

No que diz respeito aos pontos negativos, há uma série de pontuações apresentadas pelos entrevistados, em uma delas, a professora 2 (dois) 
abordou o despreparo dos docentes para receber os assistentes e sobre como funciona o Programa, relatando que não há uma preparação da Secretaria Municipal de Educação para apresenta-lo à instituição e não houve uma capacitação dos professores alfabetizadores, posto que é de responsabilidade da SEMED prestar informações relativas à execução do Programa e realizar o acompanhamento pedagógico das unidades escolares.

Além disso, outro ponto negativo é o valor pago aos assistentes, a professora 1 (um) deixou claro que o "[...] valor, eu acho muito irrisório que se paga a um auxiliar, que isso leva em algumas pessoas, não é o caso da pessoa que está aqui na escola comigo, mas em algumas pessoas pode levar a uma falta de estimulo, né? [...]" (PROFESSORA 1), sendo constado esse mesmo aspecto no depoimento da coordenadora ao destacar que "[...] então acredito que o negativo, seria o valor que eu acho irrisório [...]" (COORDENADORA PEDAGÓGICA). Em outros termos, esses profissionais não são valorizados para que desenvolvam suas habilidades com eficácia e qualidade, visto que não recebem nem auxílio mínimo para sua manutenção na escola como vale transporte e alimentação.

Dessa forma, ao analisar as entrevistas, outro ponto evidente é a formação desses profissionais, uma vez que não são qualificados para exercer o trabalho de assistente. A coordenadora evidenciou esse déficit ressaltando que seria necessário realizar "uma seleção mais dentro da área mesmo, que eu sei que o assistente não vai dar aula, ele não é professor, né? Não assume a turma, porém ele teria que ter um mínimo de psicologia, de didática, alguma coisa relacionada à sala de aula [...]" (COORDENADORA PEDAGÓGICA).

\section{CONSIDERAÇÕES FINAIS}

A construção de políticas educacionais visa à melhoria na qualidade da educação. Nesse cenário, uma problemática presente é a descontinuidade dos processos estabelecidos, visto que cabe "ressaltar, que o que se tem verificado é o dimensionamento de um programa para outro, 
assinalando a ausência de um encerramento oficial por parte do governo sobre esses com aplicação da lógica da descontinuidade" (VIÉDES; ARANDA; SANTOS, 2018, p.2). Desse modo, torna-se cada vez mais complexo desenvolver uma política que supra as necessidades, haja vista que a descontinuidade das políticas educacionais é visível e afeta diretamente a sua execução, avaliação e continuidade

A implementação da Política Nacional de Alfabetização e suas diretrizes desvaloriza toda a trajetória e os esforços dos profissionais da educação e das políticas públicas desenvolvidas em governos anteriores, bem como seus progressos, evidenciando meramente problemas relacionados à leitura e à escrita, simplificando a aprendizagem à prática de repetições de técnicas, descartando fatores culturais, sociais, econômicos, psicossociais que também estão envolvidos na aprendizagem, além de antecipar o processo de alfabetização, desrespeitando as particularidades das crianças no desenvolvimento de aquisição e na construção de conhecimentos.

Compreende-se que as rupturas das políticas públicas ao longo da história resultam em aspectos negativos para o campo da educação, tendo uma forte marca os índices de analfabetismo no país, dados que afetam a rede de ensino público, estabelecendo um desequilíbrio nas políticas, prejudicando a organização de toda a comunidade escolar, os processos organizativos e evidenciando a descontinuidade de questões teóricas de ensino e de aprendizagem, desconsiderando os avanços e limitando o processo de alfabetização, como é o caso do Programa Mais Alfabetização. É imprescindível que as políticas sejam concretizadas em uma perspectiva de continuidade, mesmo as de governo, com a finalidade de não existir rupturas nas políticas educacionais, de modo que o processo de alfabetização seja contínuo e processual.

Acerca da existência do Programa Mais Alfabetização, é possível perceber, por meio das vozes dos participantes, que a concepção posta vai de encontro à defesa de uma formação continuada dos profissionais da educação, bem como assume a desvalorização docente através da 
precarização de contrato dos assistentes, afirmando uma concepção mínima de educação, sendo respaldada pelas políticas de cunho neoliberais. Outro aspecto que cabe sinalizar é a limitação na compreensão do processo de alfabetização, estando imbuído em um paradigma simplório atrelado apenas à codificação e à decodificação das palavras.

É fundamental a construção de uma escola pública que atenda as necessidades reais dos estudantes e dos profissionais da educação, fomentando a formação continuada dos professores, agregando conhecimento e possibilitando a construção de um espaço participativo em busca de uma educação pública de qualidade para todos os envolvidos. Esse espaço necessita de políticas democráticas, com a finalidade que os agentes sociais possam envolver-se e contribuir na construção social do espaço escolar.

No entanto, cabe ressaltar que, para alcançar uma qualidade na execução das políticas educacionais, faz-se necessária a existência de políticas com a perspectiva de continuidade. Assim, deve-se considerar todos os sujeitos envolvidos na realidade escolar, de modo que sua base evidencie o cotidiano e possibilite um processo contínuo, de acordo com as carências vigentes da escola, tornando o "chão" da escola pública um espaço inclusivo, democrático, laico e que atenda às necessidades do público atendido. Eis, portanto, o desafio!

\section{REFERÊNCIAS}

BRASIL. Base Nacional Comum Curricular (BNCC). Educação é a Base. Brasília, MEC/CONSED/UNDIME, 2017.

BRASIL. Constituição (1988). Constituição da República Federativa do Brasil. Brasília, DF: Senado Federal: Centro Gráfico, 1988.

BRASIL. Instituto Nacional de Estudos e Pesquisas Educacionais Anísio Teixeira. Plano Nacional de Educação PNE 2014-2024: Linha de Base. - Brasília, DF: Inep, 2015.

BRASIL. Ministério da Educação. Secretaria de Alfabetização. PNA Política Nacional de Alfabetização/Secretaria de Alfabetização. - Brasília: MEC, SEALF, 2019.

BRASIL. Ministério da Educação - MEC. Programa Mais Alfabetização.

CAEDDIGITAL.NET, Brasil. Disponível em : < 
https://maisalfabetizacao.caeddigital.net/\#!/pagina-inicial>. Acesso em: 9 jun. de 2020.

DIONIZIO, J. A. F.; SOUZA, R. Z. Os desafios do processo de alfabetização. - Paraná Brasil, 2017.

MINAYO, M. C. S. Ciência, técnica e arte: o desafio da pesquisa social. In: MINAYO, Maria Cecília de Souza (Org.). Pesquisa Social: teoria, método e criatividade. Petrópolis, RJ: Vozes, 1994.

MORAES, A. C. A. Análise do programa mais alfabetização e precarização na formação e trabalho docente. Revista do Instituto de Políticas Públicas de Marília, Marília, v.5, n.1, p. 109-126, jan./jun., 2019.

OLIVEIRA, D. A. Das políticas de governo à política de estado: reflexões sobre a atual agenda educacional brasileira. Educação \& Sociedade, Campinas, v. 32, n. 115, p. 323-337, abr.-jun. 2011. Disponível em: < https://www.scielo.br/pdf/es/v32n1 15/v32n1 15a05.pdf>. Acesso em: 28 de fev. 2021.

OLIVEIRA, L. A. O processo de alfabetização: leitura e escrita nos anos iniciais. Trabalho de Conclusão de Curso (graduação)-Sociedade Cultural Educacional de Itapeva Faculdade de Ciências Sociais e Agrárias de Itapeva, Itapeva - São Paulo Brasil, 2014. $35 \mathrm{f}$.

PERES, P. Política Nacional de Alfabetização: entenda as polêmicas presentes na PNA. Nova Escola, São Paulo, 03 de maio de 2019. Disponível em :

<https://novaescola.org.br/conteudo/17139/entenda-as-polemicas-presentes-napolitica-nacional-de-alfabetizacao>. Acesso em: 23 jun. de 2020.

SOARES, M. Letramento: como definir, como avaliar, como medir. In: SOARES, M. Letramento: um tema em três gêneros. Belo Horizonte: Autêntica, 1999.

SOARES, M. Alfabetização e letramento. São Paulo: Contexto, 2018.

SOARES, M. Alfabetização: a questão dos métodos. São Paulo: Contexto, 2018.

VASCONCELLOS, C. S. Planejamento: Projeto de Ensino-Aprendizagem e Projeto Político - Pedagógico - elementos metodológicos para elaboração e realização. Libertad, São Paulo, 2002.

VIEDES, S. C. A.; SOUSA, S. N.; ARANDA, M. A. M. A concepção de alfabetização em programas federais: tensões e (in)certezas da Política Nacional De Alfabetização (2016-2019). Revista de Estudos Aplicados em Educação, v. 4, n. 8, jul./dez. 2019.

YIN, R. K. Estudo de Caso: planejamento e métodos. Tradução: Ana Thorell; revisão: Cláudio Damacena. Porto Alegre: Bookman, 2010.

Recebido em: 11 de fevereiro de 2021.

Aprovado em: 28 de maio de 2021.

Publicado em: 09 de junho de 2021.

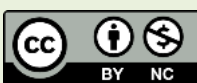

